\title{
Illness perceptions and quality of life among tuberculosis patients in Gezira, Sudan.
}

\author{
Suleiman Mohammed ${ }^{1}$, Sahal Nagla ${ }^{1}$, Sodeman Morten ${ }^{2}$, Eldony Asma ${ }^{3}$, Aro Arja ${ }^{1}$
}

1. Unit for Health Promotion Research, University of Southern Denmark (SDU), Esbjerg, Denmark.

2. Department of Infectious Diseases, Odense University Hospital, Odense, Denmark.

3. Epidemiological Laboratory, Khartoum, Sudan.

\begin{abstract}
Aims: This study aimed to answer the following research question: What is the level of illness perceptions and quality of life among TB patients in Gezira state?.

Methods: A descriptive study design was used. Newly diagnosed smear positive TB patients registered in Gezira state in $2010(n=425)$ formed the study population. The illness perceptions were measured by using Brief Illness Perceptions Questionnaire (BIPQ). Health Related Quality of Life (HRQoL) was assessed by means of the 12-item short form Health Survey questionnaire (FS-12).

Results: TB patients saw TB as having minor consequences, TB not being very well controlled by treatment, and TB as lasting long as a disease; they also associated several symptoms with TB. Furthermore, the patients had relatively poor physical and mental quality of life. Identity, consequences, personal control and emotional representations were associated with poor physical quality of life while concern about illness was associated with poor mental quality of life.

Conclusion: The illness perceptions of the TB patients might influence their adherence to treatment. The poor quality of life of the TB patients in the different areas of quality of life such as daily activities and work, calls for programmes to strengthen TB information, education and counselling.
\end{abstract}

Key words: Tuberculosis, patients, illness perception, quality of life, Gezira, Sudan

DOI: http://dx.doi.org/10.4314/ahs.v15i2.11

\section{Background}

Tuberculosis (TB) persists as a global public health problem of a serious magnitude requiring urgent attention $^{1}$. Current global efforts to control TB have three distinct but overlapping dimensions: humanitarian, public health and economic. Alleviating the illness, suffering and death of individuals caused by TB is a major humanitarian concern and calls for a patient-centered approach ${ }^{1}$.

\section{Corresponding author: \\ Suleiman Mohammed \\ Unit for Health Promotion Research, \\ University of Southern Denmark (SDU), \\ Esbjerg, Denmark. \\ Tel. +4565504241 \\ Email: drmsuleiman@gmail.com \\ Address. Niels BohrsVej 9, \\ 6700 Esbjerg, Denmark}

Illness perceptions are increasingly being shown to be related to important outcomes in a number of illnesses. There is also evidence that patients attending for medical investigations, who have already developed negative illness perceptions of their condition, are less reassured by findings showing no pathology ${ }^{2}$. A number of studies have shown that when patients hold generally negative illness perceptions about their illness (e.g. a large number of symptoms associated with the condition, more severe consequences, and longer timeline beliefs) these perceptions are associated with increased future disability and a slower recovery, independent of the initial medical severity of the condition ${ }^{3}$.

Perceptions of illness have been found to vary with cultural, ethnic and socio-economic differences ${ }^{4}$. However, there are no published studies on the issue from Sudan. Perception of symptoms by persons suffering from pulmonary tuberculosis is found to be high ${ }^{5}$. Yet, studies have shown repeatedly that only a half of the persons aware of experiencing symptoms suggestive of tuberculosis approach a modern medical facility for alleviation of suffering ${ }^{6-8}$. Studying illness perceptions in relation to TB can bring information which helps in 
improving the cure rates amongst tuberculosis patients, Materials and methods

especially in improving the present low adherence to the administered therapy. It is extremely important that a holistic view of treatment is taken in view of the complex psycho-social characteristics of the disease.

The World Health Organization (WHO) defined quality of life (QOL) as the ability of individuals to perceive their position in life within the cultural, contextual and the value systems in which they live, being in accordance with their goals, expectations, standards and concerns'. Health-related quality of life (HRQoL) is a multi-dimensional concept that associates the physical, emotional, and social components of an individual with his/her medical conditions or treatment ${ }^{10}$. HRQoL is used to distinguish health effects from other factors influencing a subject's perceptions (such as environmental factors or job satisfaction $)^{11}$

There are no published studies on HRQoL among TB patients from Sudan. A study from India has shown that the HRQOL among both active and inactive tuberculosis cases is deformed; the quality of life was affected by demographic and socio-cultural characteristics, depression, daily sleep period, treatment period and accompanying diseases ${ }^{12}$.

TB affects all the predicted fields of quality of life, such Local guidelines of research ethics were followed and as general health perception, corporal sense, psycho- a written consent was taken from the respondents. logical health, mental peace and functionality of phys- Objectives, process and expected outcome of the reical and social roles $^{12}$. Active tuberculosis, having drug search were explained to the participants and their right side effects, social isolation and stigma from relatives, to withdraw from the study at any time was explained family members and friends, as well as causing various without any place for unwanted consequences for thei symptoms such as hemoptysis, chest pain, fever, pro- current care. Absolute confidentiality of the informafuse sweating, weight loss and fatigue, affects the quality tion gathered was followed before, during and after finof life ${ }^{12}$

ishing the study.

The present study aimed to assess illness perceptions The Brief Illness Perceptions Questionnaire (BIPQ) dimensions: identity, consequences, timeline, personal control, treatment control, concern, understanding, emotional representations; quality of life covering eight dimensions: physical functioning, role-physical, bodily pain, general health, vitality, social functioning, role-emotional, and mental health as well as associations between them among TB patients in Gezira state, Sudan. The information gathered will enable the development of effective interventions to improve TB treatment adherence and to decrease TB consequences
among Gezira population in a way which fits the local cultural characteristics of the population in the state. perceptions. Translation to Arabic language and back translation was conducted. BIPQ contains the following nine items, each measuring the previously established illness perception dimensions: identity, consequences, timeline, personal control, treatment control, concern, understanding, emotional representations, and the 9th item about the causes of TB. The scale was a five-point Likert scale, with higher scores indicating stronger endorsement of that item (high identity scores indicate that the participants experienced more symptoms; high consequences score means that the participants saw their illness having major consequences; the high timeline score means that the participants thought that their illness will last for a long time; high personal control score means that the participants perceived having good control of their illness; high treatment control score means that the participants thought the treatment being extremely helpful in managing their illness; high coherence score means that the participants understood their illness; high emotional representation score means that the participants' illness affected their emotions extremely; and high illness concern score means that the participants were highly concerned about their illness). The TB causes item responses can be grouped into categories such as stress, lifestyle, heredity etc. determined by the particular illness studied. Categorical analysis can then be performed, either on just the top listed causes or all three listed causes.

In the questionnaire, the items for TB patients were formulated as follows: e.g. how much control do you feel you have over your TB disease?

Health Related Quality of Life (HRQoL) was assessed by means of the 12-item short form Health Survey questionnaire (FS-12), translation to Arabic language and back translation was conducted. The SF-12 is a generic measure of health status, encompassing 12 questions covering eight dimensions of health significantly affected by medical condition: physical functioning, role-physical, bodily pain, general health, vitality, social functioning, role-emotional, and mental health. This eight-scale profile has been summarized into two components: physical component summary (PCS) (including limitation in self-care, physical, social, role activities, severe bodily pain and frequent tiredness) and mental component summary (MCS) (including the presence of psychological distress, the limitation in usual social and role activities due to emotional problems). Later, physical and mental components for all TB patients were categorized into three levels: poor, fair and good. Cronbach's alpha was calculated for the physical and mental mponents scale showing the reliability of 0.89 for the 8 items and 0.88 for the 4 items included in the scale espectively.

The analysis of the quantitative data was done using Statistical Package for Social Sciences (SPSS) version 19.0 program. Multinomial logistic regression was conducted as dependent variable has more than two categories to predict multivariate relation of TB illness perception and quality of life among the TB patients

\section{Results}

The proportion of men was slightly higher than women; half of the patients were married and one third singles; $20 \%$ had no education and $7 \%$ had university education. The patients lived more often in the rural than in urban areas. Further, half of TB patients were without work. To answer the research question: What is the level of illness perceptions and quality of life among TB patients $(n=425)$ in Gezira state, Sudan, the following main findings are summarized:

\section{Illness perceptions}

The TB patients perceived that TB lasted long (timeline); they indicated several symptoms to TB (identity); they saw TB not being well controlled by treatment (treatment control) but they saw minor consequences from TB (consequences). Most of the patients mentioned that the most common causes of TB were: poor nutrition, poverty and contact with TB patients.

\section{Health related quality of life}

Two thirds of TB patients rated their health between good and fair while $12 \%$ rated their health as poor. About half of the TB patients reported that their disease affected their movement for long distances; 42 percent mentioned that their health affected their activities a lot. About two thirds said that their health affected their work and activities (Table 1). Half of the patients felt depressed and reported that their work performance was affected by this depression (Table1). Feeling pain had moderate effect on the activity of two thirds of the TB patients. 
Table 1: Health Related Quality of Life $(\mathrm{SF}-12)$ among TB patients $(n=425))$ in Gezira state,

Quality of life items

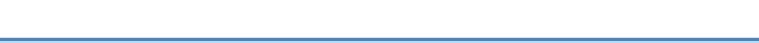

1.Health status

ms

2. Very Good Good

$\begin{array}{cc}4 . & \text { Fair } \\ 5 . & \text { Poor } \\ \text { 2.Limited activities }\end{array}$

$\begin{array}{cc}\text { 2.Limited activities } \\ 1 . & \text { Limited a lot } \\ 2 . & \text { Limited a little }\end{array}$

Not Limited at all

$\begin{array}{cc}\text { 3. Moving for a long distance } \\ 4 . \quad \text { Limited a lot } \\ 5 . & \text { Limited a little }\end{array}$

$\begin{array}{ccc}5 . & \text { Limited a little } & \text { Not limited at all } \\ 6 . & \end{array}$

4.Work or other regular activities affected by physical health

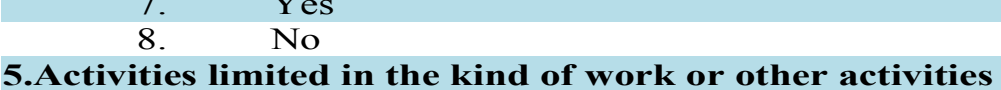

9. 10.0

6.Activities affected by fecling depressed

$11 . \quad$ Yes

195

13. Yes

$14 . \quad$ No 230

8.Pain interfere with your normal work

15. A little b

17. Moderately

$\begin{array}{ll}18 . & \text { Quite a bit } \\ 19 . & \text { Extremely }\end{array}$

\begin{tabular}{|cc|}
\hline frequency & TB patients \\
\hline 45 & $\%$ \\
\hline 37 & 11.0 \\
143 & 9.0 \\
136 & 34.9 \\
49 & 33.2 \\
\hline 165 & 12.0 \\
\hline 197 & 41.9 \\
\hline 32 & 50.0 \\
\hline 206 & 8.1 \\
\hline 179 & 50.5 \\
23 & 43.9 \\
\hline halth & 5.6 \\
\hline 116 & 74.4 \\
\hline 109 & 25.6 \\
\hline 329 & 77.4 \\
\hline 96 & 22.6 \\
\hline 195 & 45.9 \\
\hline 230 & 54.1 \\
\hline 195 & 45.9 \\
\hline 230 & 54.1 \\
\hline 57 & 14.0 \\
\hline 51 & 12.5 \\
\hline 144 & 35.4 \\
\hline 109 & 26.8 \\
\hline 46 & 11.3 \\
\hline & \\
\hline
\end{tabular}

Table 1: Health Related Quality of Life (SF-12) among TB patients $(n=425)$ in Gezira state, Sudan.

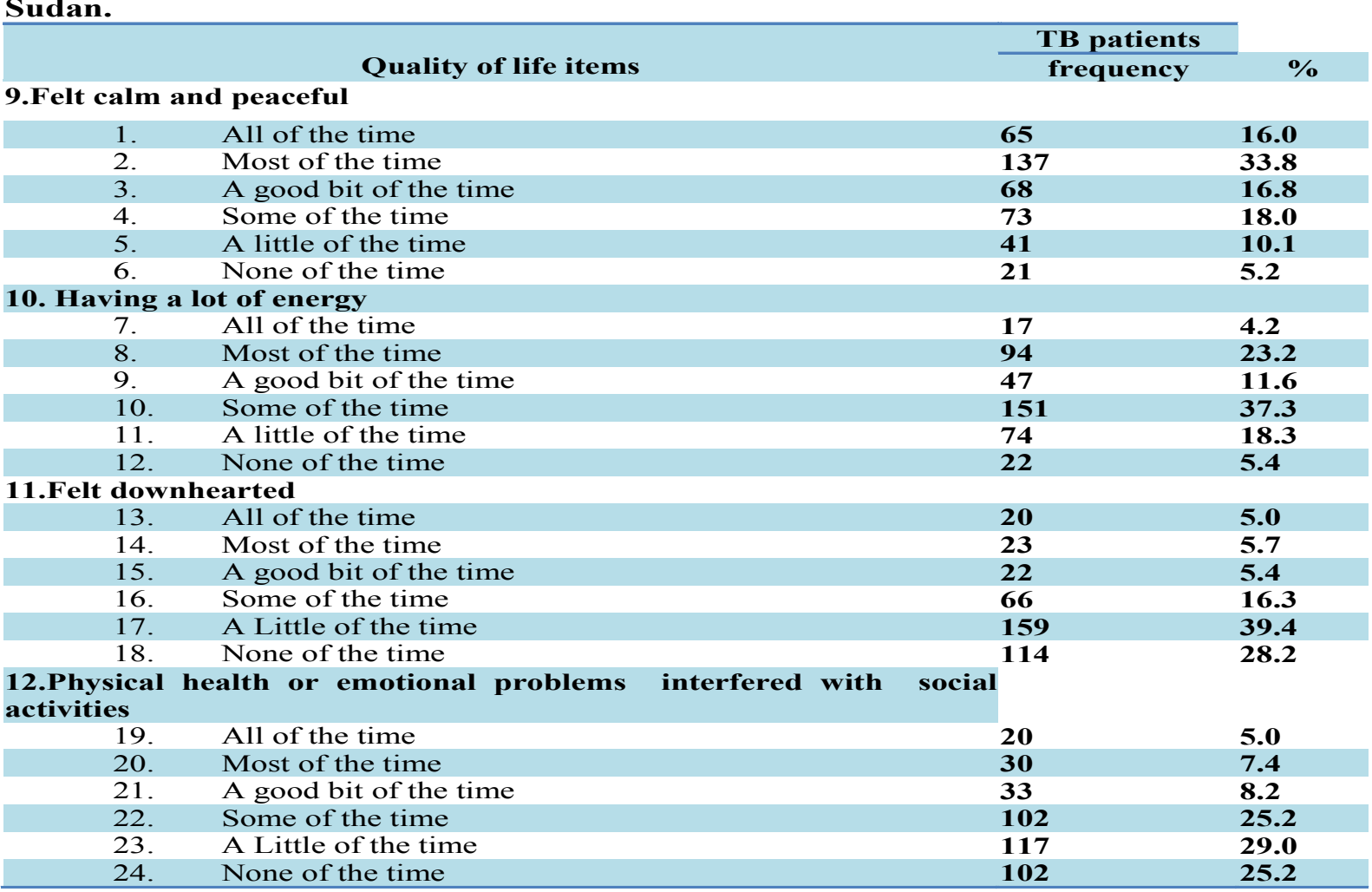

TB patients felt calm and peaceful most of the time; problems had minor effect on their social relations sometimes they felt that they had enough energy; and (Table 1). Around 80 percent of the TB patients had around two thirds felt downhearted very few times; and physical quality of life level ranging from good to fair half of the TB patients mentioned that their health while about $87 \%$ had good mental quality of life level ranging from good to fair (Table 2).

Table 2 Quality of life components among TB patients in Gezira state, Sudan

\begin{tabular}{lcc} 
& $\begin{array}{c}\text { Quality of life components } \\
\text { Physical component }\end{array}$ & TB patients $(\mathbf{n}=\mathbf{4 2 5})$ \\
\cline { 2 - 3 } & Frequency & $\mathbf{\%}$ \\
Poor & 76 & 17.9 \\
Fair & 238 & 56 \\
Good & 111 & 26.1 \\
Mental component & TB patients $(\mathbf{n}=\mathbf{4 2 5})$ & $\mathbf{\%}$ \\
& Frequency & 13.1 \\
Poor & 60 & 42.0 \\
Fair & 177 & 44.9 \\
Good & 188 & \\
\hline
\end{tabular}

In the multinomial logistic regression analysis for the ical and mental quality of life (Table 3 and 4). Being association between the two quality of life components younger, single and with low education were associated (physical and mental) and socio-demographic charac- with fair physical quality of life while, low education teristics the crude odds ratios showed that: only TB pa- and living in village setting were associated with fair tients who had lower education level had poor phys- mental quality of life (Table 3 and 4)

Table 3: Multinomial logistic regression analysis: physical component of quality of
socio-demographic characteristics among TB patients (n= 425) in Gezira state, Sudan.

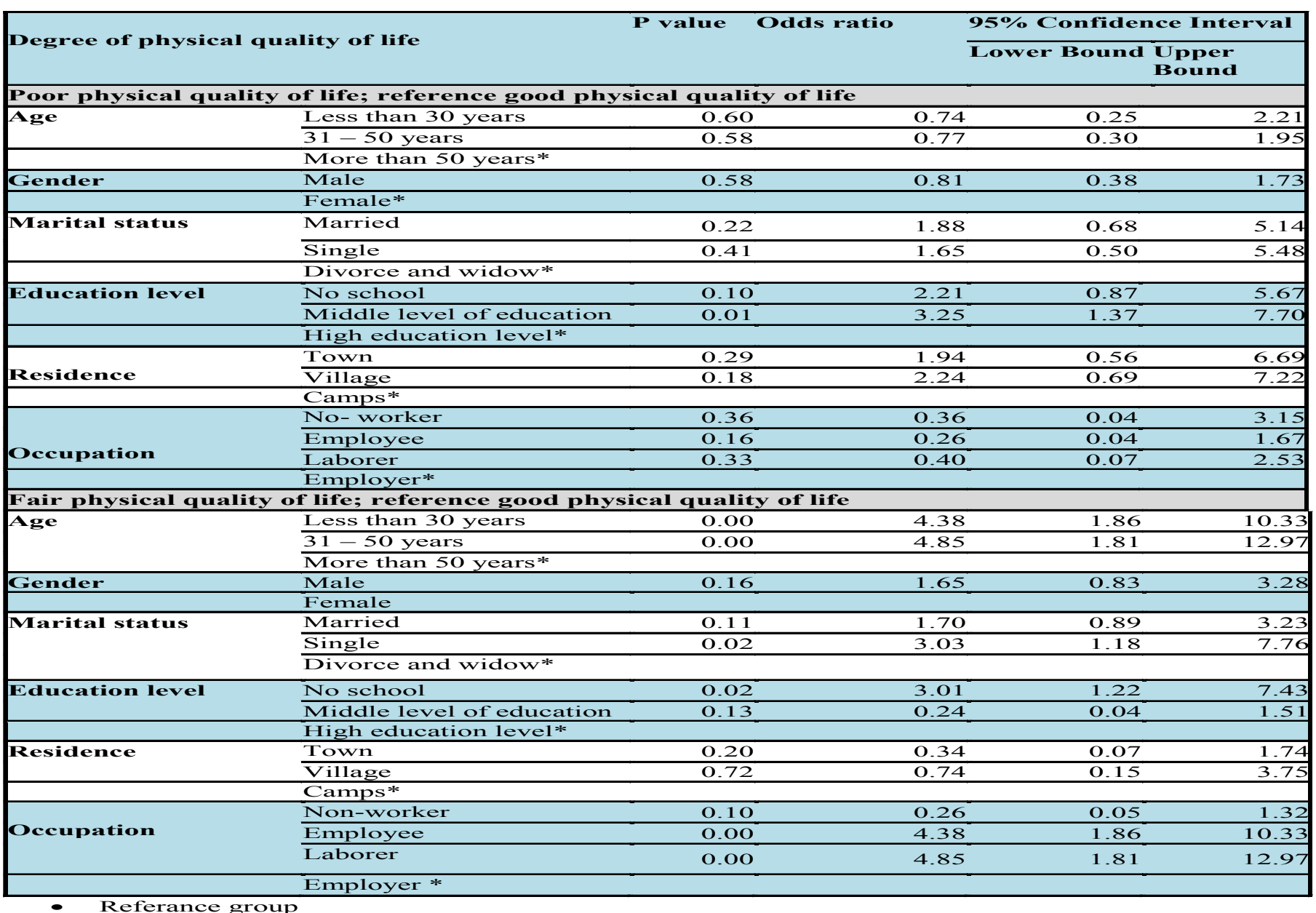

African Health Sciences Vol 15 Issue 2, June 2015 
Table 4: Multinomial logistic regression analysis: mental component of quality of life and sociodemographic characteristics among TB patients $(n=425)$ in Gezira state, Sudan

\begin{tabular}{|c|c|c|c|c|c|}
\hline \multicolumn{2}{|c|}{ Degree of mental quality of life } & P value & Odds ratio & \multicolumn{2}{|c|}{$\begin{array}{c}\text { 95\% Confidence Interval } \\
\text { Lower Bound Upper } \\
\text { Bound }\end{array}$} \\
\hline \multicolumn{6}{|c|}{ Poor mental quality of life; reference good mental quality of life } \\
\hline \multirow[t]{2}{*}{ Age } & Less than 30 years & 0.58 & 1.38 & 0.45 & 4.21 \\
\hline & $\begin{array}{l}31-50 \text { years } \\
\text { More than } 50 \text { years* }\end{array}$ & 0.51 & 0.73 & 0.28 & 1.88 \\
\hline Gender & $\begin{array}{l}\text { Male } \\
\text { Female* }\end{array}$ & 0.18 & 1.71 & 0.78 & 3.74 \\
\hline \multirow{2}{*}{$\begin{array}{l}\text { Marital } \\
\text { status }\end{array}$} & Married & 0.47 & 1.57 & 0.46 & 5.38 \\
\hline & $\begin{array}{l}\text { Single } \\
\text { Divorce and widow* }\end{array}$ & 0.85 & 0.87 & 0.20 & 3.78 \\
\hline \multirow{2}{*}{$\begin{array}{l}\text { Education } \\
\text { level }\end{array}$} & No school & 0.10 & 2.27 & 0.84 & 6.12 \\
\hline & $\begin{array}{l}\text { Middle level of education } \\
\text { High education level* }\end{array}$ & 0.03 & 2.81 & 1.10 & 7.17 \\
\hline \multirow{3}{*}{ Residence } & Town & 0.21 & 2.45 & 0.60 & 9.98 \\
\hline & $\begin{array}{l}\text { Village } \\
\text { Camps* }\end{array}$ & 0.08 & 3.28 & 0.86 & 12.52 \\
\hline & Non worker & 0.05 & 0.20 & 0.04 & 0.99 \\
\hline \multirow{3}{*}{ Occupation } & Employee & 0.57 & 0.65 & 0.15 & 2.82 \\
\hline & Employer & 0.04 & 0.19 & 0.04 & 0.95 \\
\hline & \multicolumn{4}{|c|}{ Fair mental quality of life; reference good mental quality of life } & \\
\hline \multirow[t]{2}{*}{ Age } & Less than 30 years & 0.82 & 0.91 & 0.40 & 2.06 \\
\hline & $\begin{array}{l}31-50 \text { years } \\
\text { More than } 50 \text { years* }\end{array}$ & 0.87 & 0.94 & 0.48 & 1.87 \\
\hline Gender & $\begin{array}{l}\text { Male } \\
\text { Female* }\end{array}$ & 0.34 & 1.31 & 0.75 & 2.30 \\
\hline \multirow{2}{*}{$\begin{array}{l}\text { Marital } \\
\text { status }\end{array}$} & Married & 0.69 & 0.85 & 0.38 & 1.92 \\
\hline & $\begin{array}{l}\text { Single } \\
\text { Divorce and widow* }\end{array}$ & 0.36 & 0.64 & 0.25 & 1.66 \\
\hline \multirow{2}{*}{$\begin{array}{l}\text { Education } \\
\text { level }\end{array}$} & No school & 0.97 & 1.01 & 0.53 & 1.95 \\
\hline & $\begin{array}{l}\text { Middle level of education } \\
\text { High education level* }\end{array}$ & 0.03 & 1.93 & 1.06 & 3.52 \\
\hline \multirow[t]{3}{*}{ Residence } & Town & 0.18 & 2.09 & 0.71 & 6.11 \\
\hline & $\begin{array}{l}\text { Village } \\
\text { Camps* }\end{array}$ & 0.00 & 5.61 & 1.98 & 15.88 \\
\hline & Non-worker & 0.93 & 1.06 & 0.29 & 3.90 \\
\hline \multirow[t]{3}{*}{ Occupation } & Employee & 0.83 & 1.15 & 0.32 & 4.16 \\
\hline & Laborer & 0.73 & 1.26 & 0.34 & 4.67 \\
\hline & Employer* & & & & \\
\hline
\end{tabular}

- Referance group

In the multinomial logistic regression analysis for the ratios showed that $\mathrm{TB}$ patients who did not understood association between the two quality of life compo- their illness (coherence) and had poor personal control nents (physical and mental) and the eight dimensions over their illness,had poor mental quality of life (Table of illness perception (identity, consequences, timeline, 5), while, only TB patients who had high concern about personal control, treatment control, concern, under- their illness (concern) had poor physical quality of life standing and emotional presentations) the crude odds (Table 5).
Table 5: Multinomial logistic regression analysis: physical and mental componentsof quality of life and TB illness perceptions among TB patients $(n=425)$ in Gezira state, Sudan.

\begin{tabular}{|c|c|c|c|c|c|}
\hline \multirow{2}{*}{$\begin{array}{l}\text { Quality of life components } \\
\text { dimensions }\end{array}$} & \multirow[b]{2}{*}{ B-IPQ } & \multirow[t]{2}{*}{$P$ value } & \multirow[t]{2}{*}{ Odds ratio } & \multicolumn{2}{|c|}{ 95\% Confidence Interval } \\
\hline & & & & Lower Bound & Upper Bound \\
\hline \multicolumn{6}{|l|}{ Physical component } \\
\hline \multirow{8}{*}{ Poor physical component * } & Consequences & 0.87 & 0.99 & 0.82 & 1.19 \\
\hline & Timeline & 0.95 & 0.99 & 0.75 & 1.31 \\
\hline & Personal control & 0.05 & 1.33 & 1.00 & 1.77 \\
\hline & Treatment control & 0.18 & 1.15 & 0.94 & 1.41 \\
\hline & Identity & 0.29 & 1.29 & 0.80 & 2.09 \\
\hline & Concern & 0.00 & 1.68 & 1.18 & 2.41 \\
\hline & Coherence & 0.36 & 1.13 & 0.87 & 1.45 \\
\hline & Emotional response & 0.10 & 0.82 & 0.65 & 1.04 \\
\hline \multirow[t]{8}{*}{ Fair physical component* } & Consequences & 0.80 & 1.01 & 0.92 & 1.11 \\
\hline & Timeline & 0.08 & 1.21 & 0.98 & 1.49 \\
\hline & Personal control & 0.35 & 0.92 & 0.77 & 1.10 \\
\hline & Treatment control & 0.87 & 1.01 & 0.88 & 1.16 \\
\hline & Identity & 0.16 & 1.21 & 0.93 & 1.57 \\
\hline & Concern & 0.90 & 1.01 & 0.85 & 1.20 \\
\hline & Coherence & 0.00 & 1.32 & 1.11 & 1.58 \\
\hline & Emotional response & 0.05 & 0.85 & 0.73 & 1.00 \\
\hline \multicolumn{6}{|l|}{ Mental components } \\
\hline \multirow[t]{8}{*}{ Poor mental component* } & Consequences & 0.43 & 0.90 & 0.70 & 1.16 \\
\hline & Timeline & 0.11 & 0.80 & 0.62 & 1.05 \\
\hline & Personal control & $<0.001$ & 0.66 & 0.53 & 0.82 \\
\hline & Treatment control & 0.11 & 1.19 & 0.96 & 1.47 \\
\hline & Identity & 0.83 & 1.05 & 0.67 & 1.64 \\
\hline & Concern & 0.09 & 1.30 & 0.97 & 1.74 \\
\hline & Coherence & 0.04 & 1.29 & 1.02 & 1.64 \\
\hline & Emotional response & 0.17 & 0.84 & 0.65 & 1.08 \\
\hline \multirow[t]{8}{*}{ Fair mental component* } & Consequences & 0.78 & 0.99 & 0.91 & 1.07 \\
\hline & Timeline & 0.84 & 0.98 & 0.79 & 1.22 \\
\hline & Personal control & 0.60 & 0.95 & 0.80 & 1.14 \\
\hline & Treatment control & 0.34 & 1.07 & 0.93 & 1.22 \\
\hline & Identity & 0.94 & 1.01 & 0.76 & 1.34 \\
\hline & Concern & $<.001$ & 1.51 & 1.25 & 1.82 \\
\hline & Coherence & 0.35 & 1.09 & 0.91 & 1.29 \\
\hline & Emotional response & 0.39 & 0.94 & 0.81 & 1.09 \\
\hline
\end{tabular}

Discussion

The results of this study among TB patients in Gezira, Illness perceptions are the organized cognitive rep- Sudan, showed that these patients perceived their illnes resentations or beliefs that patients have about their to be of long duration, having several TB symptoms illness. These perceptions have been found to be im- and TB treatment not being very effective. These perportant determinants of behaviour and have been asso- ceptions might affect negatively TB patients' treatment ciated with a number of important outcomes, such as adherence. Further, the emotional reactions to TB as treatment adherence and functional recovery ${ }^{14,15}$. well as limitations in their social activities might be bar- 
Ars to seeking treatment and adherence to treatment. Adherence is a challenge for the TB control programm in Sudan, as the early case detection, prompt treatment and case holding are the golden strategies in controlling $\mathrm{TB}^{24}$. Having symptoms of TB such as chronic productive cough, hemoptysis, weight loss, and perceiving the nature of TB to be an infectious disease in some patients, might initiate the feeling of guilt of infecting others and aggravating the sense of stigma. The latter is considered as a barrier for seeking and maintaining treatment ${ }^{28}$.

It is known that socio-demographic factors are associated with both illness perceptions and quality of $\operatorname{life}^{24}$ Thus it is important to tailor and deliver the appropriate TB interventions both for prevention and cure so that they suit socio-demographic characteristics.

In this study the overall quality of life among TB patients was found to be relatively poor. The association of illness perceptions with decreased quality of life has been found in a number of other illnesses (e.g. diabetes and renal disease $)^{16-21}$

Illness perceptions of patients have been shown to significantly influence both psychosocial and physical well-being and thus affect the quality of life of the patients $^{22}$. This study found that the patients highly concerned about their illness seemed to have poor mental quality of life. This is in line with findings of a study from Pakistan, which found that the majority of patients suffering from TB had impaired mental quality of life in form of depression ${ }^{23}$.

Based on the literature, depression and anxiety are very high in patients with tuberculosis. Psychiatric complications such as anxiety and depression can greatly impact quality of life of TB patients ${ }^{26}$. In our study about half of the TB patients felt depressed, which is similar to Pakistan $^{23}$; this might be due to the perception of the nature of TB as a chronic disease, severity of the symptoms and social stigma associated with the diseases ${ }^{27,28}$ Feeling of depression might affect the adherence to TB treatment, which results in high default rate. Default rate has been shown to be high in $\operatorname{Sudan}^{27}$ and can thus bring failure to control TB. This finding is supported by the study from India ${ }^{29}$. ties dimensions of health related quality, which reflects Rheumatology 1999;26: 1686-93.
4. Rabin DL, Bice TW, Starfield B. Use of health services by Baltimore Medicaid recipients. Medical Care $1974 ; 12(7): 561-570$

5. Narayan R, Thomas S, et al: Prevalence ofchest symptoms and action taken bysymptomatic in a rural community. Indian Journal Tuberculosis 1976;23:160-168. 6. Banerji D \&Andeison :A sociologicalstudy of awareness of symptoms amongpersons with pulmonary tuberculosis. Bulletin of World Health Organization 1963;29:665-683

7. Narayan R, Prabhakar S, et al: Asociological study of awareness of symptoms and action taking of person with pulmonary tuberculosis (A resurvey) Indian Journal of Tuberculosis 1 979;26:136-146.

8. Enterline E.P. \&Katherina G: A validation of info mation provided by household respondents in healt surveys. American Journal Public Health 1959; 49:205-212. 9. WHO. The World Health Organization Quality of Life assessment (WHOQOL): position paper from the World Health Organization. Social Science and Medicine Journal 1995;41(10):1403-9.

10. Khanna D, Tsevat J.Health-related quality of life-an introduction. The American Journal of Managed Care 2007;13Suppl 9:S218-23.

11. Kaplan RM, Bush JW. Health related quality of life measurement for evaluation research and policy analysis. Health Psychology Journal 1982;1:61-80.

12. Unalan $\mathrm{D}$, Soyuer $\mathrm{F}$, et al. Is the quality of life different in patients with active and inactive tuberculosis? Indian Journal of Tuberculosis 2008;55(3):127-37.

13. Broadbent E, Petrie J, Main J, and Weinman J. The Brief Illness Perception Questionnaire (BIPQ).Journal of Psychosomatic Research 2006;60:631-637.

14. Leventhal H, Benyamini $Y$, et al. Illness representations: theoretical foundations. In: Petrie KJ, Weinman J, (Eds). Perceptions of health and illness. Amsterdam: Harwood Academic; 1997:155-188.

15. Weinman J, Petrie KJ. Illness perceptions: a new paradiom for psychosomatics? Psychosomatics Research Journal 1997;42:113-116.

16. Kaptein AA, Helder DI, Scharloo M, et al. Illness perceptions and coping explain well being in patients with Huntington's disease. Psychology and Health Journal 2006;21:431-446.

17. Ponzo MG, Gucciardi E, Weiland M, et al. Gender, ethnocultural, and psychosocial barriers to diabetes

1. WHO. Forty-fourth World Health Assembly [on2. Scharloo M, Kaptein AA, et al. Patients' illness perceptions and coping as predictors of functional status w. British Journal of and inactive tuberculosis? Indian Journal of Tuberculosis 2008;55(3):127-37. 